\title{
Oligosymptomatic Reversible Posterior Leukoencephalopathy in a Patient With Lupus Nephritis
}

\author{
Alba Velazquez ${ }^{\mathrm{a}, \mathrm{b}}$, Sonia Santos ${ }^{\mathrm{a}}$, Cristina Iñiguez $^{\mathrm{a}}$
}

\begin{abstract}
Reversible posterior leukoencephalopathy (RPL) is a pathology that was first described in 1996. It is characterized by a clinical syndrome with sudden headache, altered mental status, visual impairment, seizures and radiological findings (mostly in posterior encephalic regions). It has a sudden onset which makes diagnosis more difficult. RPL has been relationed with several pathologies and use of some drugs. We report a case of a young female, diagnosed of Eritematous Systemic Lupus who developed an oligosymptomatic RPL. Although RPL frequently has a sudden onset with multiple symptoms, sometimes it can go with minimum signs, so physicians should be aware of this pathology in order to make an early diagnosis and correct treatment.
\end{abstract}

Keywords: Posterior reversible leukoencephalopathy; Eritematous systemic lupus; Lupus nephritis; Oligosymptomatic

\section{Introduction}

Reversible Posterior Leukoencephalopathy (RPL) was first described by Hinchey et al [1] in 1996. Its fisiopathology remains unclear but seems to be related to a failure of the cerebral blood pressure mechanism or to an endothelial dysfunction. This neurological syndrome is characterized by seizures (partial or generalized), sudden headache with no response to analgesia, altered mental status and visual impairment. The RPL is mainly reversible but sometimes it can have a fatal course [2]. Otherwise, as it has many different etiologies, clinical manifestations may vary.

\footnotetext{
Manuscript accepted for publication August 20, 2013

${ }^{a}$ Neurology Department of the Lozano Blesa Hospital, 15th San Juan Bosco Avenue, Postcode 50009, Zaragoza, Spain

${ }^{\mathrm{b} C o r r e s p o n d i n g ~ a u t h o r: ~ A l b a ~ V e l a z q u e z, ~ N e u r o l o g y ~ D e p a r t m e n t ~ o f ~ t h e ~}$ Lozano Blesa Hospital, 15th San Juan Bosco Avenue, Postcode 50009, Zaragoza, Spain. Email: albavelazquez83@gmail.com
}

doi: http://dx.doi.org/10.4021/jmc1463w

\section{Case Report}

An 18-year-old female, right handed, with not known allergies and medical history of Eritematous Sistemic Lupus and Lupic Nephritis (level IIIA). The year before she had been treated with ciclofosfamide and mycophenolate. The patient developed increased edema in lower limbs so she was transferred to the hospital, where she started taking again ciclofosfamide and intravenous methiprednysolone pulses. During the first days of hospitalization, she remained asymptomatic but with high blood pressure that decreased with antihypertensive drugs.

After a week, she developed a progressive mild to moderate headache, located in occipital regions, without sickness but with transitory phosphenes in her left visual field. Blood pressure at the moment was 210/110, cardiac frequency was $80 \mathrm{bpm}$, capillary glucose was $110 \mathrm{mg} / \mathrm{dL}$ and temperature was $36.4^{\circ} \mathrm{C}$.

The neurological examination showed normal level of

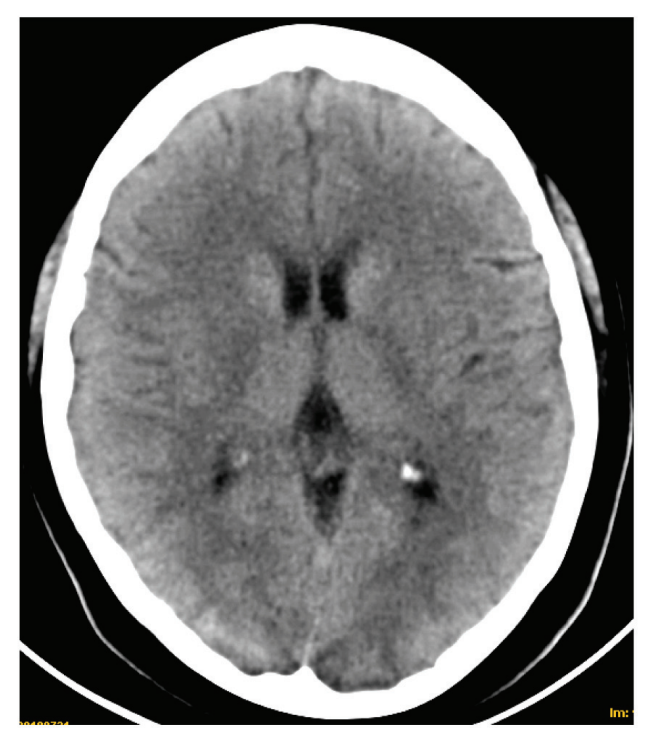

Figure 1. CT scan showing hipodense lesions in both occipital regions. 


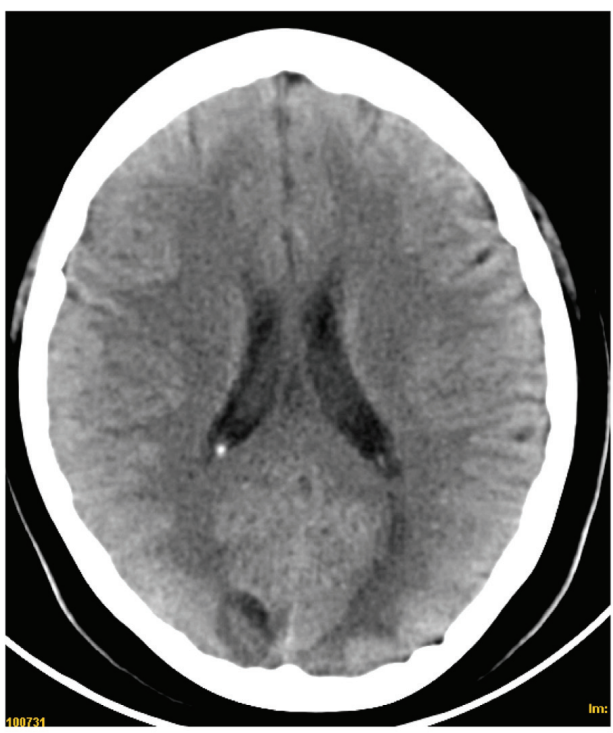

Figure 2. CT scan showing hipodense lesions in both occipital regions.

consciousness, there were no meningeal signs or pupillary defects and no weakness was observed. There were normal deep osteotendinous reflexes and no language alteration. The only abnormal sign was a left homonimous hemianopsy.

An urgent computerized tomography (CT) scan showed two hipodense lesions (Fig. 1-3) located in both occipital lobes.

Urgent blood exams showed: low hemoglobin $(8.8 \mathrm{mg} /$ $\mathrm{dL}$ ) with hematocrit of $26 \%, 6.2 \mathrm{mill} / \mathrm{mm}^{3}$ leukocytes, 79 $\mathrm{mill} / \mathrm{mm}^{3}$ platelets, urea $0.7 \mathrm{~g} / \mathrm{dL}$, creatinine $1.1 \mathrm{mg} / \mathrm{dL}$, normal electrolytes, glucose $86 \mathrm{mg}$ and proteinuria of $7.9 \mathrm{~g} / \mathrm{L}$.

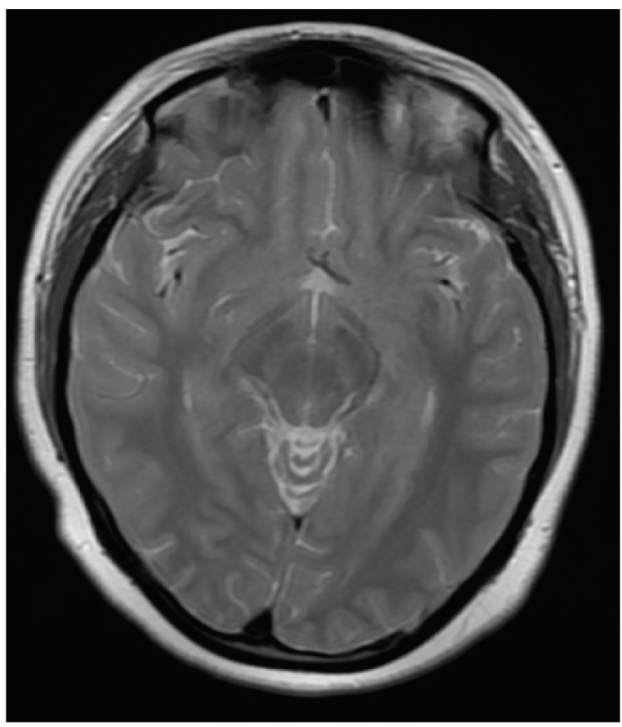

Figure 4. Normal MRI scan (T2 sequences).

Search of lupic anticoagulant and anticardiolipin antibodies were negative. An urgent encephalogram and transthoracic echocardiogram were normal. The urgent transcranial ultrasound study showed minimum asymmetry between deep venous systems to superficial one, there were no signs of vasospasm or significant stenosis.

High blood pressure was normalized after intravenous drugs during the next hours and the patient was given paracetamol so she had complete recovery in the following 24 hours. According to the abnormalities found in the urgent transcranial ultrasound an anticoagulant treatment was

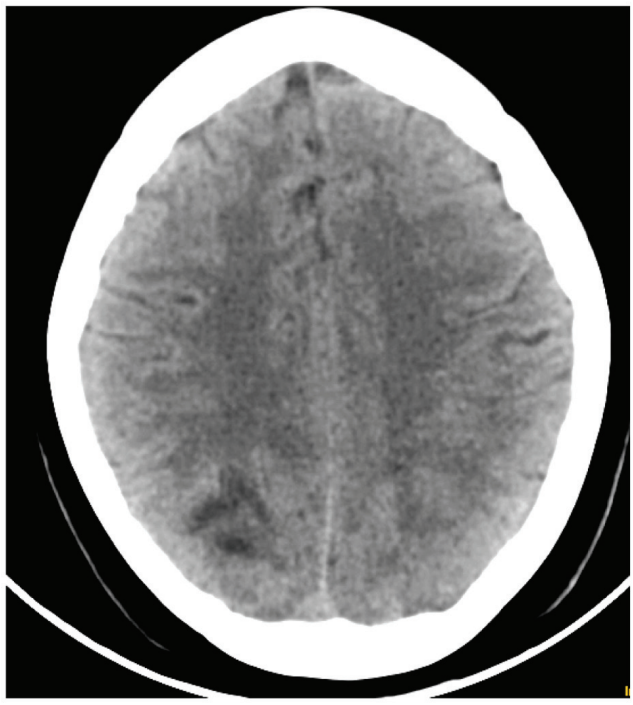

Figure 3. CT scan showing hipodense lesion in right occipital lobe.

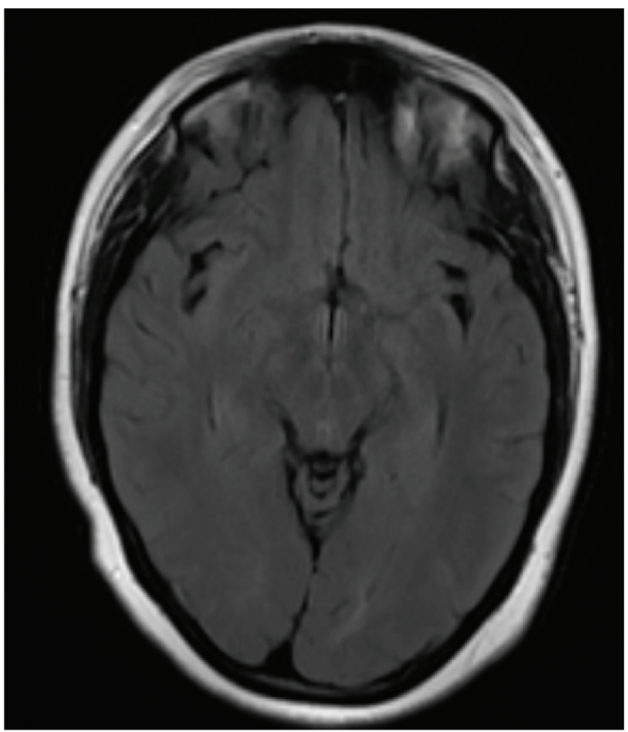

Figure 5. Normal MRI scan (T1 sequences) 
started using low weight heparin.

A Magnetic Resonance (MRI) with diffusion/weighted sequences and angiography was done after 48 hours of the onset and was completely normal (Fig. 4, 5). The second transcranial ultrasound (four days after the onset) did not show abnormalities.

\section{Discussion}

There has been described many etiologies $[3,4]$ for this neurological syndrome, such as severe hypertension, renal diseases, immunossupressive drugs, eclampsia or preeclampsia, vasculitis, use of contrasts or even blood transfusion. Pathogenesis is yet unclear [5], it seems to be related to a failure of the cerebral blood regulation mechanism after an unexpected increase of blood pressure. It may consequently develop a vasogenic brain edema which has predilection for the vertebrobasilar system [3] due to its deficitary sympatic inervation. Clinical signs may vary and the radiological findings are not pathognomonic. It is common to find symmetrical lesions in white matter, mostly in posterior regions such as occipital lobes, cerebellum and even brainstem although grey matter and anterior regions could be rarely affected.

The variability of clinical and radiological findings leads into a wide differential diagnosis $[4,5]$ including venous thrombosis, central nervous system vasculitis, stroke, central nervous system infections or even the onset of a demielinating disease.

An urgent CT scan is mandatory [3] to discard other pathologies but the MRI is the best exam to diagnose early ischemic lesions, especially when using the diffusion/weighted sequences. The neuroradiographic exams are really useful in patients with an atypical onset like our patient, who had significantly slight signs and symptoms according to the typical RPL [6-9]. Physicians should be aware of this variability because it may hinder a correct diagnosis and treatment.

\section{References}

1. Hinchey J, Chaves C, Appignani B, Breen J, Pao L, Wang A, Pessin MS, et al. A reversible posterior leukoencephalopathy syndrome. N Engl J Med. 1996;334(8):494500 .

2. Golombeck SK, Wessig C, Monoranu CM, Schutz A, Solymosi L, Melzer N, Kleinschnitz C. Fatal atypical reversible posterior leukoencephalopathy syndrome: a case report. J Med Case Rep. 2013;7(1):14.

3. Lopez-Garcia F, Amoros-Martinez F, Sempere AP. [A reversible posterior leukoencephalopathy syndrome]. Rev Neurol. 2004;38(3):261-266.

4. Primavera A, Audenino D, Mavilio N, Cocito L. Reversible posterior leucoencephalopathy syndrome in systemic lupus and vasculitis. Ann Rheum Dis. 2001;60(5):534537.

5. Perez E, Campos J, Novoa D, Blanco J. Leucoencefalopatía posterior reversible en una paciente con lupus eritematoso sistemico. Med Clin (Barc) 2007;128:598.

6. Alurralde AM, di Egidio M, Saizar R, Consalvo D, Villa AM. [Reversible posterior leucoencephalopathy syndrome: a case report and review of its physiopathology based on neuroradiological findings]. Rev Neurol. 2004;38(6):541-544.

7. Mavragani CP, Vlachoyiannopoulos PG, Kosmas N, Boletis I, Tzioufas G, Voulgarelis M. A case or reversible leucoencephalopathy síndrome after rituximab infusion. Rheumatology 2004;43:1451-1452.

8. Mahad DJ, Hellden A, Jarvis J, Mitra D, Gholkar A, Chinnery PF. Aciclovir induced posterior leucoencephalopathy. J Neurol Neurosurg Psychiatry. 2005;76(9):13081309.

9. Biswa MP, Saravana P, Yogendra K, Aman G. Reversible posterior leucoencephalopathy síndrome in an elderly maleo $\mathrm{n}$ suntinib therapy. Br J Pharmacol 2011;71(5):777-779. 